\title{
About the Optimized Design of the Parking Space on the Campus of a College
}

\author{
Xin Wang1, Yunhui Wang', Chong Hu${ }^{1}$ \\ ${ }^{1}$ School of Data Science and Software Engineering, Baoding University, Baoding, China \\ ${ }^{2}$ School of Automotive and Electronic Engineering, Baoding University, Baoding, China \\ Email: wangxincloud@163.com
}

How to cite this paper: Wang, X., Wang, Y.H. and Hu, C. (2020) About the Optimized Design of the Parking Space on the Campus of a College. American Journal of Computational Mathematics, 10, 221-229. https://doi.org/10.4236/ajcm.2020.102011

Received: March 5, 2020

Accepted: April 25, 2020

Published: April 28, 2020

Copyright $\odot 2020$ by author(s) and Scientific Research Publishing Inc. This work is licensed under the Creative Commons Attribution International License (CC BY 4.0).

http://creativecommons.org/licenses/by/4.0/ (c) (i) Open Access

\begin{abstract}
In recent years, with the large increase in the number of motor vehicles in colleges and universities and the lag in campus planning, the relative shortage of parking spaces on campus has become increasingly serious. Taking Baoding College as an example, this article analyzes the current situation of static traffic on campus and finds out the problem of parking on campus through questionnaire surveys and field surveys. Analyze the growth trend of the number of motor vehicles based on the data, use the GM $(1,1)$ model and the linear fitting model to predict the number of motor vehicles in the future, and determine the size and layout of the parking lot based on the campus size, functional zoning, and road layout. The big campus-based parking system planning method based on big data can effectively solve the problems of small sample data, low accuracy, and poor timeliness of traditional methods, which improves the practicability and scientificity of planning results.
\end{abstract}

\section{Keywords}

Static Traffic, Parking Space Planning, GM $(1,1)$, Linear Fitting

\section{Introduction}

Due to the rapid development of society and the improvement of people's living standards, it is not unusual to own a private car, and college teachers are no exception. The number of college teachers who use private cars as a means of trav$\mathrm{el}$ is increasing year by year, and it is no longer news for students to drive to school [1] [2]. The relationship between colleges and the society is getting closer and closer, and the number of social transportation facilities entering colleges is also increasing rapidly, which has caused great traffic dangers to the highly crowded campus environment. At the same time, the disorderly parking and random access of motor vehicles on the campus will also generate a large amount 
of exhaust gas and noise pollution, which will destroy the clean, comfortable, civilized and harmonious campus environment. Therefore, it is an urgent task to build a harmonious campus to plan campus parking and eliminate hidden dangers of traffic safety [3] [4].

\section{Investigation and Analysis of Campus Parking Problems}

\subsection{Problems with Campus Parking}

This article takes Baoding University as an example. Through field surveys, it is found that the following problems exist in parking on campus:

1) Parking spaces in some areas no longer meet the daily parking needs of teachers and students, let alone the increasing demand for parking each year. Parking saturation is now reaching most of the campus.

2) Unreasonable parking space planning [5].

3) Roadside traffic signs and markings are lacking and have no guiding effect; lack of standardized management and serious parking disorder.

This article makes a more reasonable design plan for the above problems.

\subsection{Questionnaire Survey on Parking Issues}

A questionnaire survey was conducted on teachers and students. A total of 1000 questionnaires were sent and 910 were retrieved. The survey results found that with the promotion of a green and low-carbon lifestyle, people will use green and low-carbon transportation on sunny days even if they own a private car. About $43 \%$ of teachers may use private cars for transportation, and about $25 \%$ of teachers are unfamiliar with the location of the parking lot, and there are still "difficult parking" situations. Generally choose to park near the destination or a short walk to the destination after parking. It is best to walk within 100 meters and less than 5 minutes.

There are still many problems with the on-campus parking lot. In addition to the problems shown above, the respondents also made the following suggestions: build a carport to reduce the sun and divide the parking area. It is shown in Table 1.

\subsection{Campus Vehicle Parking Features}

1) The number of cars parked on campus is mainly small motor vehicles.

2) Most parking people will choose a parking space near the destination.

3) The campus roads have a single function, mainly for non-motorized vehicles and pedestrian traffic, and small motor vehicle traffic.

4) Lack of traffic signal instructions.

\section{Analysis and Forecast of Parking Demand}

This paper uses the GM $(1,1)$ model [6] and the linear fitting model [7] to make predictions simultaneously. The actual number of parking spaces at various locations in the school from 2013 to 2018 is shown in Table 2. 
Table 1. School parking area.

\begin{tabular}{|c|c|c|c|c|c|}
\hline No. & $\begin{array}{l}\text { Existing } \\
\text { parking } \\
\text { space } \\
\text { (number) }\end{array}$ & $\begin{array}{l}\text { Daily } \\
\text { parking } \\
\text { number } \\
\text { (vehicles) }\end{array}$ & $\begin{array}{l}\text { Whether } \\
\text { it is sufficient } \\
\text { at the current } \\
\text { stage }\end{array}$ & $\begin{array}{l}\text { Parking } \\
\text { facilities } \\
\text { planning } \\
\text { service scope. }\end{array}$ & $\begin{array}{l}\text { Concentrated } \\
\text { parking time }\end{array}$ \\
\hline $\begin{array}{l}\text { 1) Near the } \\
\text { stadium }\end{array}$ & 0 & 22 & no & $\begin{array}{l}\text { Teachers of the } \\
\text { Department of } \\
\text { Physical Education }\end{array}$ & $\begin{array}{l}7: 50-12: 10 \mathrm{AM} \\
1: 50-6: 10 \mathrm{PM}\end{array}$ \\
\hline $\begin{array}{l}\text { 2) Music } \\
\text { building, near } \\
\text { the art building, }\end{array}$ & 46 & 40 & yes & $\begin{array}{l}\text { Teachers of the } \\
\text { music and art } \\
\text { departments }\end{array}$ & $\begin{array}{l}7: 50-12: 10 \mathrm{AM} \\
1: 50-6: 10 \mathrm{PM}\end{array}$ \\
\hline $\begin{array}{l}\text { 3) In front of the } \\
\text { information } \\
\text { technology } \\
\text { building }\end{array}$ & 0 & 14 & no & $\begin{array}{l}\text { Teachers in the } \\
\text { Department of } \\
\text { Computer and } \\
\text { English, }\end{array}$ & $\begin{array}{l}7: 50-12: 10 \mathrm{AM} \\
1: 50-6: 10 \mathrm{PM}\end{array}$ \\
\hline $\begin{array}{l}\text { 4) West side of } \\
\text { science building, } \\
\text { south side }\end{array}$ & 32 & 40 & no & $\begin{array}{l}\text { Teachers in the } \\
\text { Department of Politics } \\
\text { and Law, Education, }\end{array}$ & $\begin{array}{l}7: 50 \text { - 12:10AM } \\
1: 50 \text { - 6:10PM }\end{array}$ \\
\hline $\begin{array}{l}\text { 5) East of } \\
\text { building F, } \\
\text { south lab } \\
\text { building }\end{array}$ & 25 & 35 & no & $\begin{array}{l}\text { Teachers in the } \\
\text { Department of Physics, } \\
\text { a small number of } \\
\text { administrative staff }\end{array}$ & $\begin{array}{l}7: 50-12: 10 \mathrm{AM} \\
1: 50-6: 10 \mathrm{PM}\end{array}$ \\
\hline $\begin{array}{l}\text { 6) Foreign } \\
\text { languages } \\
\text { building, west } \\
\text { of math and } \\
\text { computer } \\
\text { building }\end{array}$ & 50 & 16 & yes & $\begin{array}{l}\text { Teachers in the } \\
\text { Department of } \\
\text { Mathematics and } \\
\text { Computers, Foreign } \\
\text { Languages and } \\
\text { Chinese }\end{array}$ & $\begin{array}{l}7: 50-12: 10 \mathrm{AM} \\
1: 50-6: 10 \mathrm{PM}\end{array}$ \\
\hline
\end{tabular}

Table 2. Number of parking spaces on campus from 2013 to 2018 (Unit: vehicles).

\begin{tabular}{ccccccc}
\hline Years; Parking Position & 1 & 2 & 3 & 4 & 5 & 6 \\
\hline 2013 & 9 & 18 & 7 & 30 & 16 & 19 \\
2014 & 12 & 24 & 9 & 40 & 21 & 25 \\
2015 & 17 & 33 & 12 & 55 & 29 & 33 \\
2016 & 19 & 36 & 13 & 60 & 32 & 36 \\
2017 & 21 & 37 & 14 & 63 & 34 & 38 \\
2018 & 22 & 39 & 14 & 65 & 35 & 38 \\
\hline
\end{tabular}

\subsection{Model Establishment and Solution Analysis}

Based on the existing data, the GM $(1,1)$ model is used to make prediction analysis on the number of motor vehicles.

Let the original reference data be listed as

$$
x^{(0)}=\left(x^{(0)}(1), x^{(0)}(2), \cdots, x^{(0)}(n)\right)
$$

Do an accumulation (AGO) to generate a sequence

$$
\begin{aligned}
x^{(1)} & =\left(x^{(1)}(1), x^{(1)}(2), \cdots, x^{(1)}(n)\right) \\
& =\left(x^{(1)}(1), x^{(1)}(1)+x^{(0)}(2), \cdots, x^{(1)}(n-1)+x^{(0)}(n)\right)
\end{aligned}
$$


among them,

$$
x^{(1)}(k)=\sum_{i=1}^{k} x^{(0)}(i), k=1,2, \cdots, n
$$

Find the mean series

$$
z^{(1)}(k)=0.5 x^{(1)}(k)+0.5 x^{(1)}(k-1), k=2,3, \cdots, n
$$

then

$$
z^{(1)}=\left(z^{(1)}(2), z^{(1)}(3), \cdots, z^{(1)}(n)\right)
$$

So the gray differential equation is established as

$$
x^{(0)}(k)+a z^{(1)}(k)=b, k=2,3, \cdots, n
$$

The corresponding albino differential equation is

$$
\frac{\mathrm{d} x^{(1)}}{\mathrm{d} t}+a x^{(1)}(t)=b
$$

Remember

$$
u=(a, b)^{\mathrm{T}}, \quad Y=\left(x^{(0)}(2), x^{(0)}(3), \cdots, x^{(0)}(n)\right)^{\mathrm{T}}, \quad B=\left(\begin{array}{ccc}
-z^{(1)}(2) & 1 \\
-z^{(1)}(3) & 1 \\
\vdots & \vdots \\
-z^{(1)}(n) & 1
\end{array}\right) .
$$

Then the least squares method [8] is used to find

$$
J(\hat{u})=(Y-B \hat{u})^{\mathrm{T}}(Y-B \hat{u})
$$

Reaching the minimum

$$
\hat{u}=(a, b)^{\mathrm{T}}=\left(B^{\mathrm{T}} B\right)^{-1} B^{\mathrm{T}} Y .
$$

Then solving the whitening differential equation

$$
x^{(1)}(k+1)=\left(x^{(0)}(1)-\frac{b}{a}\right) \mathrm{e}^{-a k}+\frac{b}{a}, k=1,2, \cdots, n-1
$$

Analyze the results by error: use the step deviation test.

First, the step ratio $\lambda(k)$ is calculated from the reference data $x^{(0)}(k-1)$, $x^{(0)}(k)$ and then the corresponding step ratio deviation $\rho(k)=1-\left(\frac{1-0.5 a}{1+0.5 a}\right) \lambda(k)$ is obtained using the development coefficient $a$.

If $\rho(k)<0.2$, it can be considered to meet the general requirements; if $\rho(k)<0.1$, it is considered to meet the higher requirements

\subsection{Model Application}

Take position 1 (in front of the stadium) as an example.

The data brought into position 1 is the original data predicting the number of parkings at that position in the next three years, then 


$$
x^{(0)}=\left(x^{(0)}(1), x^{(0)}(2), \cdots, x^{(0)}(6)\right)=(9,12,17,19,21,22)
$$

The grade ratio can be obtained as

$$
\lambda=(\lambda(2), \lambda(3), \cdots, \lambda(6))=(0.75,0.71,0.89,0.90,0.95)
$$

It can be seen that except for $\lambda(2), \lambda(3)$, all other ratios fall within the tolerable coverage $\left(\mathrm{e}^{-\frac{2}{7}}, \mathrm{e}^{\frac{1}{4}}\right)$, then the series $x^{(0)}$ cannot be used as the data for the model GM $(1,1)$ for gray prediction [9], and a translation transformation is required.

Take the constant and translate it

$$
y^{(0)}(k)=x^{(0)}(k)+c, k=1,2, \cdots, n
$$

which is

$$
y^{(0)}(k)=x^{(0)}(k)+4, k=1,2, \cdots, n
$$

Get the sequence

$$
y^{(0)}=\left(y^{(0)}(1), y^{(0)}(2), \cdots, y^{(0)}(n)\right)=(13,16,21,23,25,26)
$$

Its ratio is

$$
\lambda_{y}=\left(\lambda_{y}(2), \lambda_{y}(3), \lambda_{y}(4), \lambda_{y}(5), \lambda_{y}(6)\right)=(0.81,0.76,0.91,0.92,0.96)
$$

Both fall within the tolerance coverage $\left(\mathrm{e}^{-\frac{2}{7}}, \mathrm{e}^{\frac{1}{4}}\right)$, and the series $y^{(0)}$ can be used as the data for the model GM $(1,1)$ for grey prediction.

Accumulate $y^{(0)}$ once to generate a sequence

$$
y^{(1)}=\left(y^{(1)}(1), y^{(1)}(2), \cdots, y^{(1)}(6)\right)=(13,29,50,73,98,124)
$$

Mean series

$$
z^{(1)}(k)=0.5 y^{(1)}(k)+0.5 y^{(1)}(k-1), k=2,3, \cdots, n
$$

get

$$
z^{(1)}=\left(z^{(1)}(2), z^{(1)}(3), \cdots, z^{(1)}(6)\right)=(21,39.5,61.5,85.5,111)
$$

also

$$
\begin{gathered}
Y=\left(y^{(0)}(2), y^{(0)}(3), \cdots, y^{(0)}(6)\right)^{\mathrm{T}}=(16,21,23,25,26)^{\mathrm{T}}, \\
B=\left(\begin{array}{ll}
-z^{(1)}(2) & 1 \\
-z^{(1)}(3) & 1 \\
-z^{(1)}(4) & 1 \\
-z^{(1)}(5) & 1 \\
-z^{(1)}(6) & 1
\end{array}\right)=\left(\begin{array}{cc}
-21 & 1 \\
-39.5 & 1 \\
-61.5 & 1 \\
-85.5 & 1 \\
-111 & 1
\end{array}\right),
\end{gathered}
$$

and so

$$
B^{\mathrm{T}}=\left(\begin{array}{ccccc}
-21 & -39.5 & -61.5 & -85.5 & -111 \\
1 & 1 & 1 & 1 & 1
\end{array}\right) .
$$


Calculated using the formula in EXCEL

$$
\begin{gathered}
B^{\mathrm{T}} B=\left(\begin{array}{cc}
25414.75 & -318.5 \\
-318.5 & 5
\end{array}\right) \\
\left(B^{\mathrm{T}} B\right)^{-1}=\left(\begin{array}{cc}
0 & 0.01 \\
0.01 & 0.99
\end{array}\right)
\end{gathered}
$$

Then when the minimum value is obtained by the method of least squares,

$$
\hat{u}=(a, b)^{\mathrm{T}}=\left(B^{\mathrm{T}} B\right)^{-1} B^{\mathrm{T}} Y=(-0.10,15.58)^{\mathrm{T}},
$$

That is $a=-0.10, b=15.58$.

So the gray differential equation is established as

$$
y^{(0)}(k)-0.1 z^{(1)}(k)=15.58
$$

The corresponding albino differential equation is

$$
\frac{\mathrm{d} y^{(1)}}{\mathrm{d} t}-0.1 x^{(1)}(t)=15.58
$$

Solve the above formula

$$
y^{(1)}(k+1)=\left(13-\frac{15.58}{-0.1}\right) \mathrm{e}^{0.1 k}+\frac{15.58}{-0.1}=168.8 \mathrm{e}^{0.1 k}-155.8, k=1,2,3,4,5
$$

The step deviation test becomes

$$
\begin{aligned}
\rho(k) & =1-\left(\frac{1-0.5 a}{1+0.5 a}\right) \lambda(k)=1-\left(\frac{1-0.5 \times(-0.1)}{1+0.5 \times(-0.1)}\right) \lambda(k) \\
& =1-\left(\frac{1.05}{0.95}\right) \lambda(k)=1-1.11 \lambda(k), k=2,3,4,5,6
\end{aligned}
$$

when $k=2, \lambda(k)=0.81, \rho(k)=0.0984$; when $k=3, \lambda(k)=0.76$, $\rho(k)=0.1546$;

when $k=4, \lambda(k)=0.91, \rho(k)=-0.0131$; when $k=5, \lambda(k)=0.92$, $\rho(k)=-0.0209$;

when $k=6, \lambda(k)=0.96, \rho(k)=-0.0670$;

It can be seen that all $\rho(k)$ are less than 0.2 , which meets the general requirements. In other words, the model can be used to predict the number of parking.

In the same way, this model can be used to get the predicted number of other locations. The calculation results using EXCEL are shown in Table 3.

Table 3. GM Forecast of Parking Lots in the Next Three Years (Unit: Vehicles).

\begin{tabular}{ccccccc}
\hline Years; Parking Position & 1 & 2 & 3 & 4 & 5 & 6 \\
\hline 2019 & 26 & 45 & 16 & 75 & 41 & 44 \\
2020 & 29 & 49 & 18 & 82 & 45 & 48 \\
2021 & 33 & 54 & 19 & 91 & 49 & 52 \\
\hline
\end{tabular}




\subsection{Linear Fitting Model}

Linear fitting: Knowing several discrete function values of a function, by adjusting several pending coefficients in the function, the difference between the function and the set of known points is minimized. If the pending function is linear, it is called a linear fit.

\subsection{Model Application}

This article knows the number of parking spaces in a campus from 2013 to 2018, that is, some discrete points are known. Then you can fit these known scattered points to find an approximate function that minimizes the total deviation from the actual number of vehicles, and then use the trend of this function to predict the parking demand in the next three years.

Take campus location 1 as an example. The number of vehicles at position 1 from 2013 to 2018 is plotted on a scatter chart, as shown in Figure 1.

From the scatter point trend in the figure, it can be seen that the image is approximately a linear function. Suppose $y=a x+b$ that the points $(1,9),(2,12)$, $(3,17),(4,19),(5,21),(6,22)$ are taken in, and the calculation can be obtained $a=2.6857, b=7.2667$, the formula $y=2.6857 x+7.2667$ is obtained. The prediction map obtained by EXCEL is shown in Figure 2 .

According to $0<R^{2}<1$ and $R^{2}$ the closer to 1 , the smaller the error, and the above trend line $R^{2}=0.9467$ shows that the error caused by this linear formula $y=2.6857 x+7.2667$ is extremely small and can be predicted.

Similarly, the number of parking places in other locations can be obtained by using excel, as shown in Table 4.

\section{Parking Capacity Analysis}

Combine Tables 3-5.

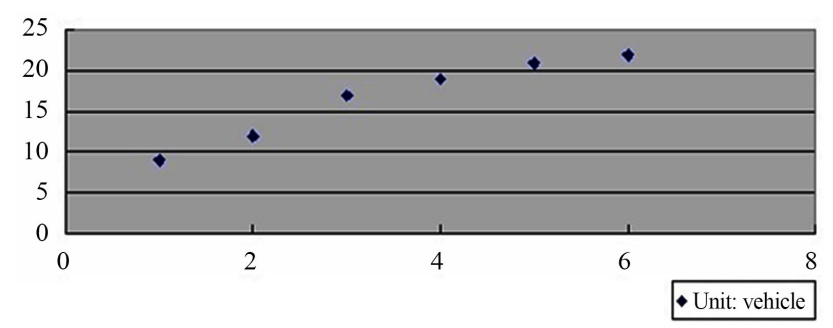

Figure 1. Number of parkings at position 1.

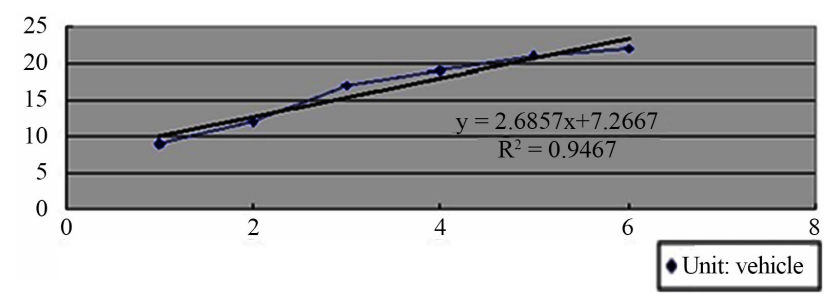

Figure 2. Position 1 linear fit prediction. 
Table 4. Linear fitted predictions of the number of parking lots in the next three years (Unit: vehicles).

\begin{tabular}{ccccccc}
\hline Years; Parking Position & 1 & 2 & 3 & 4 & 5 & 6 \\
\hline 2019 & 26 & 47 & 17 & 77 & 42 & 45 \\
2020 & 29 & 50 & 18 & 84 & 45 & 49 \\
2021 & 31 & 54 & 20 & 91 & 49 & 53 \\
\hline
\end{tabular}

Table 5. Predicted number of parking lots in the next three years (Unit: vehicles).

\begin{tabular}{|c|c|c|c|c|c|c|c|c|c|c|c|c|}
\hline \multirow{2}{*}{ Years Position } & \multicolumn{2}{|c|}{1} & \multicolumn{2}{|c|}{2} & \multicolumn{2}{|c|}{3} & \multicolumn{2}{|c|}{4} & \multicolumn{2}{|c|}{5} & \multicolumn{2}{|c|}{6} \\
\hline & GM & Linear & GM & Linear & GM & Linear & GM & Linear & GM & Linear & GM & Linear \\
\hline 2019 & 26 & 26 & 45 & 47 & 16 & 17 & 75 & 77 & 41 & 42 & 44 & 45 \\
\hline 2020 & 30 & 29 & 49 & 50 & 18 & 18 & 83 & 84 & 45 & 45 & 48 & 49 \\
\hline 2021 & 34 & 31 & 54 & 54 & 19 & 20 & 91 & 91 & 50 & 49 & 52 & 53 \\
\hline
\end{tabular}

It can be seen from the above table that the predicted value of GM is similar to the predicted value of linear fitting. Because the purpose of this study is to ensure the parking needs of teachers and students, as many parking spaces as possible are installed without affecting the campus road system, drainage system, landscape planning, and as close to the building as possible.

Due to the vigorous development of computer technology in recent years, the application of mathematics is no longer confined to the fields of natural science, engineering technology, etc., but has penetrated all areas of life with unprecedented depth and breadth. The rise of mathematical modeling has better turned practical problems in life into mathematical languages and solved them mathematically. This article is to solve the unreasonable problem of campus parking space planning by mathematical modeling. Find out the problem through investigation and analysis, and combine the appropriate model to analyze and predict the data. It not only predicts the number of motor vehicles in the future, but also makes effective and reasonable distribution plans for parking spaces through data. It has a certain theory for improving the campus environment, using parking resources reasonably and effectively, and eliminating potential traffic safety hazards that may arise and realistic meaning.

\section{Funding}

Supported by Hebei Higher Education Teaching Research and Practice Project (2017GJJG261); Hebei Province Education Department Hebei University Science and Technology Research Youth Fund Project (QN2017502); Baoding University Transformation Development Research Fund Project (2017Z01); Natural Science Research Project of Baoding University (2012Z11).

\section{Conflicts of Interest}

The authors declare no conflicts of interest regarding the publication of this paper. 


\section{References}

[1] Editorial Department of "China Highway Journal" (2016) A Summary of Academic Research on Traffic Engineering in China 2016. China Journal of Highway and Transport, 29, 1-161.

[2] Zhao, J.W., Peng, J. and Peng, F.L. (2016) On the Comprehensive Utilization of Underground Space in College Campus: A Sustainable Development Mode of Campus Space. Urban Planning International, 31, 104-111. https://doi.org/10.22217/upi.2015.056

[3] Peng, H.Q. and Zhang, G.W. (2017) Parking Standards Preparation and Smart Parking-Record of the 45th Meeting of "Transportation $7+1$ Forum". Journal of Transportation Systems Engineering and Information Technology, 17, 2-7+249.

[4] Marshall, N.L. (2018) Forecasting the Impossible: The Status Quo of Estimating Traffic Flows with Static Traffic Assignment and the Future of Dynamic Traffic Assignment. Research in Transportation Business \& Management, 29, 85-92. https://doi.org/10.1016/j.rtbm.2018.06.002

[5] Wang, Y. and Li, J.J. (2017) Discussion on Motor Vehicle Traffic Planning and Management Method of Longdong University. Housing and Real Estate, 32, 160-227.

[6] Wang, L., Sha, X.Y. and Xue, Y. (2016) Improved GM $(1,1)$ Grey Prediction Model and Its Application. Statistics \& Decision, 10, 74-77.

[7] Chen, L.B. and Zheng, Y.Q. (2012) Research on Curve Fitting Based on Least Square Method. Journal of Wuxi Institute of Technology, 11, 52-55.

[8] Zhang, Y.T. and Jia, Y.M. (2017) Analysis and Realization of Algebraic Polynomial Curve Fitting in Least Square Method. Computer \& Digital Engineering, 45, 637-639+654.

[9] Kong, X., Wang, L. and Feng, Y.H. (2018) Application Status and Prospect of Grey Forecasting GM $(1,1)$ Model. Journal of Qilu University of Technology, 32, 49-53. 